\title{
Correction to: Influence of nutrient status on the biohydrogen and lipid productivity in Parachlorella kessleri: a biorefinery approach
}

\author{
Seham M. Hamed ${ }^{1,2,3}$ (D) $\cdot$ Rahul Vijay Kapoore $^{2,4} \cdot$ Mahendra P. Raut $^{2} \cdot$ Seetharaman Vaidyanathan ${ }^{2} \cdot$ Phillip C. Wright $^{3}$ \\ Published online: 2 December 2020 \\ (C) Springer-Verlag GmbH Germany, part of Springer Nature 2020
}

Correction to: Applied Microbiology and Biotechnology (2020) 104:10293-10305 https://doi.org/10.1007/s00253-020-10930-3

The published online version contain a small error with Phillipe's affiliation. It should be 2,3 instead of 4 .

The correct presentation is given above.

Publisher's note Springer Nature remains neutral with regard to jurisdictional claims in published maps and institutional affiliations.

The online version of the original article can be found at https://oi.org/ 10.1007/s00253-020-10930-3

Seham M. Hamed

seham_moussa939@yahoo.com

1 Soil Microbiology Department, Soils, Water and Environment, Research Institute, Agricultural Research Centre, P.O.175,

El-Orman, Giza, Egypt

2 Advanced Biomanufacturing Centre, Department of Chemical and Biological Engineering, The University of Sheffield, Sheffield S1 3JD, UK

3 School of Engineering, Faculty of Science, Agriculture and Engineering, Devonshire Building, Newcastle University, Newcastle upon Tyne NE1 7RU, UK

4 Department of Biosciences, College of Science, Swansea University, Swansea SA2 8PP, UK 